\title{
Substantiation of the additional prescription of magnetotherapy in the complex of rehabilitation of children with concomitant diseases of the nervous system during remission of cancer
}

\section{SHAPOVALOVA Hanna ${ }^{1}$, SHMAKOVA Iryna ${ }^{\text {, }}$ MOKIIENKO Andrii ${ }^{\text {, }}$ GUSHCHA Sergey ${ }^{2}$, PLAKIDA Alexander ${ }^{1}$}

(cc) BY-NC-ND Balneo and PRM Research Journal DOI: http://dx.doi.org/10.12680/balne0.2021.422 Vol.12, No.1, March 2021 p: 73-76

Corresponding author: PLAKIDA Alexander: E-mail: aplakida@mail.ru

${ }^{1}$ Odessa National Medical University, Odessa, Ukraine ${ }^{2}$ State Institution «Ukrainian Research Institute of Medical Rehabilitation and Balneology of the Ministry of Health of Ukraine», Odessa, Ukraine

\begin{abstract}
Introduction. The increase in the number of children with oncological diseases requires development of effective methods of medical rehabilitation. Purpose: To determine the effectiveness of the use of low-frequency magnetotherapy (LFMT) in children with diseases of the nervous system, manifested in the period of remission of oncological diseases (OD) in the complex of sanatorium rehabilitation (SRR). Methods: Children with OD at the stage of rehabilitation in a sanatorium underwent a clinical examination: medical history, concomitant pathology, complaints, clinical examination, assessment of neurological status; instrumental studies: electroencephalography (EEG) - assessment of the bioelectrical activity of the brain; echoencephalography (EchoEG) - assessment of CSF dynamics; Doppler ultrasound (USDG) - assessment of cerebral circulation. For 25 children with concomitant diseases of the nervous system during the period of OD remission (17 people) and solid tumors ( 8 people), in addition to the general complex of SRR, magnetotherapy was prescribed for the cervical-collar zone according to the following method: magnetic induction 20 - $30 \mathrm{mT}$, exposure 10 - 15 minutes, every other day, for a course of 5 procedures. Results: The use of the therapeutic complex TFR with the additional prescription of magnetotherapy can reliably reduce children's complaints in remission of the OD for the impaired activity of the nervous system. According to the USDG indicators, statistically significant positive changes in cerebral hemodynamics were established. The results of ultrasound echoEG indicate the improvement of CSF dynamics. According to the EEG data, positive changes in the state of brain electrogenesis were established. Conclusion: The effectiveness of LFMT in children in the period of remission of oncohematological diseases with concomitant diseases of the nervous system has been substantiated.
\end{abstract}

Keywords: children, oncological diseases, sanatorium rehabilitation, low-frequency magnetic therapy,

\section{Introduction}

Today, the rate of childhood morbidity with malignant neoplasms is steadily increasing in Ukraine and around the world $(1,2,3)$. The problem is complicated by the fact that modern methods of treating the vast majority of malignant neoplasms in children have a damaging effect on normal tissues and structures of the body, including the central nervous system (CNS), which contributes to the development of side effects associated with dysregulatory pathology (4). Therefore, medical rehabilitation should be an obligatory part of modern antitumor treatment programs. One of the components of medical rehabilitation is physiotherapy - the use of various physical factors, among which low-frequency magnetic therapy (LFMT) should be mentioned. The therapeutic effect of magnetotherapy is based on the physiological effects of a static or alternating magnetic field: the appearance of weak electric currents in living tissues, which alter the transmembrane potential of cells and the permeability of the cell membrane. The nervous, endocrine and cardiovascular systems are more susceptible to the influence of a low-frequency magnetic field. LFMT normalizes the autonomic functions of the body, reduces the increased vascular tone and, thus, has a certain hypotensive effect. Due to the increase in the oscillatory movements of the shaped elements, blood plasma proteins, blood circulation is activated in various organs and tissues, and trophic and regenerative processes are enhanced. Under the influence of LFMT, the formation of releasing factors of the hypothalamus and tropic hormones of the pituitary gland increases, which stimulates the function of the adrenal glands, thyroid gland, gonads, and other endocrine glands (5). The use of LFMT improves microcirculation, suppresses the inflammatory cellular response, increases the excitability threshold of pain receptors, reduces 
muscle hypertonicity, and stimulates reparative processes (6). The authors have established the effectiveness of the use of LFMT to increase the speed of conduction of impulses along the nerve fibers, reduce perineural edema, increase the excitability of the central nervous system (CNS) $(7$, $8,9)$. The data on the therapeutic effects of LFMT are given: vasodilator, anti-inflammatory, angioprotective, trophic, hypocoagulant, hypotensive, antispasmodic, etc. $(10,11,12,13)$. The above indicates the possibility of studying the effectiveness of magnetic therapy in the complex of sanatorium-resort rehabilitation (SRR) of children with concomitant diseases of the nervous system in the period of remission of oncological diseases.

Purpose of the work: to study the dynamics of clinical and clinical, and instrumental parameters in children with concomitant diseases of the nervous system in the period of remission of cancer with the additional appointment of low-frequency magnetotherapy.

\section{Materials and methods.}

The algorithm of examination of sick children at the stage of rehabilitation in a sanatorium State Institution "Specialized clinical sanatorium named after V.P. Chkalov" of the Ministry of Health of Ukraine, Odessa, included a general clinical examination (medical history, presence of concomitant pathology, complaints, clinical examination), assessment of neurological status; instrumental studies: electroencephalography (EEG) - evaluation of the bioelectrical activity of the brain; echoencephalography (EchoEG) - assessment of cerebrospinal fluid dynamics; Doppler ultrasound assessment of cerebral circulation (14). The general complex of sanatorium-resort rehabilitation (SRR) for children with cancer (accompanied by parents) included:

- a gentle motor regime, climatotherapy, dietary nutrition; physiotherapy;

- singlet-oxygen cocktail,

- children's herbal tea (holosas with ascorbic acid),

- programs of psychological assistance to sick children and their parents.

Group 1 consisted of 25 children with concomitant diseases of the nervous system in the period of cancer remission - (17 people) and solid tumors (8 people) in the period of remission for more than 5 years, who were additionally prescribed magnetotherapy against the background of the general SRR complex (they used the ALIMP- 1) on the cervical-collar zone according to the following method: magnetic induction $20-30 \mathrm{mT}$, exposure 10 - 15 minutes, every other day, for a course of 5 procedures. Group 2 consisted of 30 children with concomitant diseases of the nervous system in the period of cancer remission, received a general complex SRR without LFMT.

\section{Results and its discussion.}

Table 1 illustrates the positive dynamics of all complaints in children who received a medical complex with the additional use of magnetotherapy. These dynamics (weakness, fatigue, dizziness, intolerance to transport, and stuffiness) significantly exceeded the indicators in children prescribed a general complex of treatment.

According to the USDG indicators, statistically significant positive changes in cerebral hemodynamics in children of group 1 were established, which were accompanied by a decrease in the manifestations of cerebral angioedema, asymmetry of blood circulation and venous dyshemia, an increase in the circulatory reserve, and an improvement in the adaptive capabilities of the autoregulation apparatus and cerebral circulation (Table 2).

According to the indicators of ultrasound EchoEG of children of the 1st group, an improvement in CSF dynamics was revealed in the form of a statistically significant decrease of intracranial hypertension and the frequency of registration of additional echo signals (Table 3 ). It should also be emphasized that the hypertensive-CSF syndrome manifestations are halved, and the pulsation index decreases threefold.

In children of the 1st group, when analyzing the EEG, positive changes in the state of brain electrogenesis were found (Table 4). The state of electrogenesis was characterized by the normalization of the bioelectrical activity of the brain, accompanied by a statistically significant improvement in the functional activity of the cortex. This emphasizes the regulatory (optimizing) effect of LFMT on the functional state of the cerebral cortex. No significant changes in local pathology were revealed.

The immediate results of treatment of children in groups 1 and 2 are shown in Table 5. More positive changes were obtained in patients of group 1, which indicates the advantage of using LFMT. 
The facts established by us are confirmed by other researchers, who cite data that using a magnetic field leads to a decrease in the side effects of radiation and chemotherapy of tumors. This is due to the protective effect of magnetic induction up to $30 \mathrm{mT}$ from radiation; the influence of a magnetic field on the activity of immune reactions in cancer patients $(15,16)$. In clinical work, the effectiveness of the use of artificial magnetic fields in the rehabilitation of children with malignant tumors has been proven (17). This is since that artificial electromagnetic fields restore the normal rhythm of the activity of the of the central nervous system's regulatory centers, which contributes to the restoration of the activity of the integral central nervous system and, accordingly, the course of the vital processes of the organism.

\section{Conclusions.}

1. The use of the medical complex SCR with the additional purpose of magnetic therapy can significantly reduce the children's complaint in remission with concomitant diseases of the nervous system.

2. Statistically significant positive changes in cerebral hemodynamics were found according to the indicators of ultrasound. Ultrasound results of EchoEG indicate an improvement in cerebrospinal fluid dynamics. According to EEG, positive changes in the state of electrogenesis of the brain.

Thus, it can be considered justified to use lowfrequency magnetic therapy in the sanatorium rehabilitation of children in the period of remission of cancer with concomitant pathology of the nervous system.

\section{References:}

1. Tkachenko VI, Rimar YaYu. Morbidity and prevalence of malignant neoplasms of the thyroid land in Ukraine and Kyiv region after the Chernoby 1 Nuclear Power Plantaccident. 2019;15(2):152 - 157 . doi: 10.22141/22240721.15.2.2019.166109.

2. Rykov MYu, Baibarina EN, Chumakova OV, PolyakovVG. Epidemiology of cancer in children in the Russian Federation: analysis of key indicatorsand ways to overcome the defects of statistical data. Oncopediatria

Oncopediatrics.2017;4(3):159-176. (In Russian). doi: 10.15690/onco.v4i3.1747.

3. Ward E, DeSantis C, Robbins A, Kohler B, Jemal A. Childhood and adolescent cancer statistics, 2014. CA Cancer J Clin. 2014 Mar-Apr;64(2):83-103. doi: 10.3322/caac.21219.

4. Volodin NN, Kasatkin VN, Tseitlin GYa. et al. Strategy of medical, psychological and social rehabilitation for children with haematological and oncological diseases. Oncohematology. 2015;10(1):7-15. (In Russian). doi:10.17650/1818-8346-2015-1-7-15.

5. UlashscikVS.

Magnettherapycurrentunderstandingofmrechanismsofmagnetfi eldactiononbody. Healthcare. 2015;11:21-29. (In Russian). http://www.zdrav.by/pdf/2015/Zdrav11.pdf

6. Karateev AE, Pogozheva EYu, Sukhareva ML, Lila AM, Ivanov AV. Et al. Evaluation of the efficiency and safety of magnet therapy for osteoarthritis. Results of the multicenter blind placebo-controlled study COSMO (CLinical Evaluation of Current Magnet Therapy for Osteoarthritis). Rheumatology Science and Practice. 2020;58(1):55-61. (In Russian). https://cyberleninka.ru/article/n/otsenka-effektivnosti-ibezopasnosti-magnitoterapii-pri-osteoartrite-rezultatymnogotsentrovogo-slepogo-platsebokontroliruemogo

7. Cichoń N, Czarny P, Bijak M, Miller E, Śliwiński T, Szemraj J, Saluk-Bijak J. Benign Effect of Extremely Low-Frequency Electromagnetic Field on Brain Plasticity Assessed by Nitric Oxide Metabolism during Poststroke RehabilitationOxidative Medicine and Cellular Longevity. 2017;Article ID 2181942. https://doi.org/10.1155/2017/2181942

8. Isaković J, Gorup D, Mitrečić D. Molecular mechanisms of microglia- and astrocyte-driven neurorestoration triggered by application of electromagnetic fields.Croat Med J. 2019;60(2):127-140. doi:10.3325/cmj.2019.60.127.

9. Abdulla FA, Alsaadi S, Sadat-Ali MIR, Alkhamis F, Alkawaja H, Lo S. Effects of pulsed low-frequency magnetic field therapy on pain intensity in patients with musculoskeletal chronic low back pain: study protocol for a randomised double-blind placebo-controlled trial. BMJ Open. 2019;9:e024650. doi:10.1136/bmjopen-2018-024650.

10. Ushakov AA. Practical physiotherapy. - 2nd ed., Rev. and add Moscow: LLC «Medical Information Agency», 2009. 608 p. (in Russian).

11. Richard HW, Funk, Lilla Knels, Antje Augstein, Rainer Marquetant, Hermann F. Dertinger, «Potent Stimulation of Blood Flow in Fingers of Volunteers after Local Short-Term Treatment with Low-Frequency Magnetic Fields from a Novel Device», Evidence-Based Complementary and Alternative Medicine. 2014; Article ID 543564. https://doi.org/10.1155/2014/543564

12. Mattsson MO, Simkó M. Emerging medical applications based on non-ionizing electromagnetic fields from $0 \mathrm{~Hz}$ to $10 \mathrm{THz}$. Med Devices (Auckl). 2019;12:347-368. https://doi.org/10.2147/MDER.S214152

13. Polk C. Therapeutic Applications of Low Frequency Electric and Magnetic Fields. In: Lin J.C. (eds) Advances in Electromagnetic Fields in Living Systems. Advances in Electromagnetic Fields in Living Systems, Vol 1. Springer, Boston, MA. 1994. https://doi.org/10.1007/978-1-4615-254244

14. Markov MS. Magnetic field therapy: a review. Electromagn Biol Med. 2007;26(1):1-23. doi: 10.1080/15368370600925342. PMID: 17454079 .

15. Frantsiyants EM, Sheiko EA. Antitumor effect of electromagnetic fields and their effect on pain in experimental and clinical oncology. Research'n Practical Medicine Journal. 2019;6(2):86-99. doi: 10.17709/2409-2231-2019-6-2-9.

16. Ashdown CP, Johns SC, Aminov E. et al. Pulsed LowFrequency Magnetic Fields Induce Tumor Membrane Disruption and Altered Cell Viability.Biophys J. 2020;118(7):1552-1563. doi:10.1016/j.bpj.2020.02.013.

17. Grushina TI. Physiotherapy in the Medical Rehabilitation of Children with Malignant Tumors. Oncopediatria Oncopediatrics. 2018;15(3):164-174. (In Russian). doi: 10.15690/onco.v5i3.1934. 
Table 1. Dynamics of complaints in children of group 1 and Group 2, $(\mathrm{M} \pm \mathrm{m})$

\begin{tabular}{|l|c|c|c|c|}
\hline \multirow{2}{*}{ Complaints } & \multicolumn{2}{|c|}{ Group } & \multicolumn{2}{c|}{ Group 2} \\
\cline { 2 - 5 } & Before treatment & After treatment & Before treatment & After treatment \\
\hline Weakness, fatigue & $22(88,0 \pm 6,5)$ & $6(24,0 \pm 8,5)^{*}$ & $26(86,7 \pm 6,2)$ & $18(60,0 \pm 9,0)^{*} \bullet$ \\
\hline Anxiety & $10(40,0 \pm 9,8)$ & $2(8,0 \pm 5,4)^{*}$ & $12(40,0 \pm 8,9)$ & $6(20,0 \pm 7,3)$ \\
\hline Mood lability, depression & $11(44,0 \pm 9,9)$ & $4(16,0 \pm 7,3)^{*}$ & $6(20,0 \pm 7,3)$ & $4(13,3 \pm 6,2)$ \\
\hline Poor appetite & $7(28,0 \pm 9,0)$ & $3(12,0 \pm 6,5)$ & $8(26,7 \pm 8,0)$ & $6(20,0 \pm 7,3)$ \\
\hline Irritability & $15(60,0 \pm 9,8)$ & $5(20,0 \pm 8,0)^{*}$ & $18(60,0 \pm 8,9)$ & $10(33,3 \pm 8,6)^{*}$ \\
\hline Sleep disorders & $8(32,0 \pm 9,3)$ & $1(4,0 \pm 3,9)^{*}$ & $10(33,3 \pm 8,6)$ & $6(20,0 \pm 7,3)$ \\
\hline Attention deficit disorder & $15(60,0 \pm 9,8)$ & $6(24,0 \pm 8,5)^{*}$ & $18(60,0 \pm 8,9)$ & $10(33,3 \pm 8,6)^{*}$ \\
\hline Headaches & $18(72,0 \pm 9,0)$ & $8(32,0 \pm 9,3)^{*}$ & $21(70,0 \pm 8,4)$ & $15(50,0 \pm 9,1)$ \\
\hline $\begin{array}{l}\text { Dizziness, intolerance of } \\
\text { transport, shortness of breath }\end{array}$ & $19(76,0 \pm 8,5$ & $6(24,0 \pm 8,5)^{*}$ & $22(73,3 \pm 8,0)$ & $18(60,0 \pm 8,9) \bullet$ \\
\hline Feeling of a "lump" in the throat & $12(48,0 \pm 9,9)$ & $2(8,0 \pm 5,4)^{*}$ & $14(46,7 \pm 9,1)$ & $8(26,7 \pm 8,1)$ \\
\hline Cold and wet palms & $7(28,0 \pm 9,0)$ & $2(8,0 \pm 5,4)$ & $8(26,7 \pm 8,1)$ & $6(20,0 \pm 7,3)$ \\
\hline Short-term pain in the heart & $10(40,0 \pm 9,8)$ & $4(16,0 \pm 7,3)$ & $12(40,0 \pm 8,9)$ & $8(26,7 \pm 8,1)$ \\
\hline Tachycardia & $5(20,0 \pm 8,0)$ & $2(8,0 \pm 5,4)$ & $6(20,0 \pm 7,3)$ & $6(20,0 \pm 7,3)$ \\
\hline
\end{tabular}

Note. $*-p<0.05$ - the probability of the difference between the indicators before and after treatment;

- $-\mathrm{p}<0.05-$ the probability of the difference between the achieved indicators of the complexes after treatment

Table 2. Dynamics of indicators of ultrasound of the main vessels of the head and neck in children of group 1 and group 2

\begin{tabular}{|l|c|c|c|c|}
\hline \multirow{2}{*}{\multicolumn{1}{|c|}{ Indicators }} & \multicolumn{2}{|c|}{ Group 1 } & \multicolumn{2}{c|}{ Group 2 } \\
\cline { 2 - 5 } & Before treatment & After treatment & Before treatment & After treatment \\
\hline Cerebral angiodystonia & $17(68,0 \pm 9,3)$ & $10(40,0 \pm 9,8)^{*}$ & $21(70,0 \pm 8,4)$ & $15(50,0 \pm 9,1)$ \\
\hline Decreased blood circulation & $20(80,0 \pm 8,0)$ & $10(40,0 \pm 9,8)^{*}$ & $24(80,0 \pm 7,3)$ & $20(66,7 \pm 8,6)$ \\
\hline Asymmetry of blood circulation & $18(72,0 \pm 9,0)$ & $10(40,0 \pm 9,8)^{*}$ & $22(73,3 \pm 8,1)$ & $18(60,0 \pm 8,9)$ \\
\hline $\begin{array}{l}\text { Decreased adaptive capacity of } \\
\text { the autoregulation apparatus }\end{array}$ & $15(60,0 \pm 9,8)$ & $8(32,0 \pm 9,3)^{*}$ & $18(60,0 \pm 8,9)$ & $14(46,7 \pm 9,1)$ \\
\hline Venous dysgemia, & $22(88,0 \pm 6,5)$ & $12(48,0 \pm 9,9)^{*}$ & $27(90,0 \pm 5,5)$ & $20(66,7 \pm 8,6)^{*}$ \\
\hline
\end{tabular}

Note. $*$ - $\mathrm{p}<0,05$ - probability of difference between indicators before and after treatment.

Table 3. Dynamics of ultrasound EchoEG in children of group 1 and Group 2, $(\mathrm{M} \pm \mathrm{m})$

\begin{tabular}{|l|c|c|c|c|}
\hline \multirow{2}{*}{\multicolumn{1}{|c|}{ Indicators }} & \multicolumn{2}{|c}{ Group 1 } & \multicolumn{2}{c|}{ Group 2 } \\
\cline { 2 - 5 } $\begin{array}{l}\text { Phenomena of intracranial } \\
\text { hypertension, \% }\end{array}$ & Before treatment & After treatment & Before treatment & After treatment \\
\hline Hypertensive-CSF syndrome, \% & $10(40,0 \pm 9,8)$ & $5(20,0 \pm 8,0)$ & $12(40,0 \pm 8,9)$ & $10(33,3 \pm 8,6)$ \\
\hline $\begin{array}{l}\text { Increasing the index of } \\
\text { pulsations, \% }\end{array}$ & $6(24,0 \pm 8,5)$ & $2(8,0 \pm 5,4)$ & $7(23,3 \pm 7,7)$ & $4(13,3 \pm 6,2)$ \\
\hline Additional Echoes, \% & $8(32,0 \pm 9,3)$ & $2(8,0 \pm 5,4)^{*}$ & $10(33,3 \pm 8,6)$ & $10(33,3 \pm 8,6) \bullet$ \\
\hline
\end{tabular}

Note. $*$ - $\mathrm{p}<0.05$ - the probability of the difference between the indicators before and after treatment;

- $-\mathrm{p}<0.05$ - the probability of the difference between the achieved indicators of the complexes after treatment

Table 4. Dynamics of EEG parameters in children of group 1 and Group 2, $(\mathrm{M} \pm \mathrm{m})$

\begin{tabular}{|l|c|c|c|c|}
\hline \multirow{2}{*}{\multicolumn{1}{|c|}{ Indicators }} & \multicolumn{2}{|c|}{ Group 1 } & \multicolumn{2}{c|}{ Group 2 } \\
\cline { 2 - 5 } & Before treatment & After treatment & Before treatment & After treatment \\
\hline Changes in electrogenesis, \% & $15(60,0 \pm 9,8)$ & $8(32,0 \pm 9,3)^{*}$ & $18(60,0 \pm 8,9)$ & $16(53,3 \pm 9,1)$ \\
\hline Changes in functional activity, \% & $15(60,0 \pm 9,8)$ & $7(28,0 \pm 9,0)^{*}$ & $18(60,0 \pm 8,9)$ & $14(46,7 \pm 9,1) \bullet$ \\
\hline
\end{tabular}

Note. $*-p<0.05$ - the probability of the difference between the indicators before and after treatment;

- $-\mathrm{p}<0.05$ - the probability of the difference between the achieved indicators of the complexes after treatment

Table 5. Immediate results of treatment of children in groups 1 and 2, abs. number of patients, $(\mathrm{G} \pm \mathrm{mg}) \%$

\begin{tabular}{|l|c|c|c|c|c|c|}
\hline \multirow{3}{*}{ Treatment results } & \multicolumn{3}{|c|}{ Group 1 } & \multicolumn{3}{c|}{ Group 2 } \\
\cline { 2 - 7 } & \multicolumn{3}{|c|}{ Neurological syndrome } & \multicolumn{3}{c|}{ Neurological syndrome } \\
\cline { 2 - 7 } & $\begin{array}{c}\text { vegetative- } \\
\text { vascular, } \\
\mathrm{n}=8\end{array}$ & $\begin{array}{c}\text { astheno- } \\
\text { neurotic } \\
\mathrm{n}=10\end{array}$ & $\begin{array}{c}\text { vascular } \\
\mathrm{n}=7\end{array}$ & $\begin{array}{c}\text { vegetative- } \\
\text { vascular, } \\
\mathrm{n}=10\end{array}$ & $\begin{array}{c}\text { astheno- } \\
\text { neurotic } \\
\mathrm{n}=12\end{array}$ & $\begin{array}{c}\text { Cerebro- } \\
\text { vascular } \\
\mathrm{n}=8\end{array}$ \\
\hline Improvements & $3(37,5 \pm 17,1)$ & $5(50,0 \pm 15,8)$ & $2(28,6 \pm 17,1)$ & $2(20,0 \pm 12,6)$ & $2(16,7 \pm 10,8)$ & \\
\hline Slight improvement & $4(50,0 \pm 17,7)$ & $4(40,0 \pm 15,5)$ & $4(57,1 \pm 18,7)$ & $2(20,0 \pm 12,6)$ & $2(16,7 \pm 10,8)$ & $6(75,0 \pm 15,3)$ \\
\hline Unchanged & $1(12,5 \pm 11,7)$ & $1(10,0 \pm 9,5)$ & $1(14,3 \pm 13,2)$ & $4(40,0 \pm 15,6)$ & $5(41,6 \pm 14,2)$ & $2(25,0 \pm 15,3)$ \\
\hline Deterioration & & & & $2(20,0 \pm 12,6)$ & $3(25,0 \pm 12,5)$ & \\
\hline
\end{tabular}

